Int. J. Electrochem. Sci., 15 (2020) 3327 - 3346

International Journal of

ELECTROCHEMICAL

SCIENCE

WWW.electrochemsci.org

Mini Review

\title{
The Application of Nanomaterials as Electrode Modifiers for the Electrochemical Detection of Ascorbic Acid: Review
}

\author{
Saifeldin M. Siddeeg ${ }^{1,2}$, Norah Salem Alsaiari ${ }^{3}$, Mohamed A. Tahoon ${ }^{1, *}$ and Faouzi Ben Rebah ${ }^{1,4}$ \\ ${ }^{1}$ Department of Chemistry, College of Science, King Khalid University, P.O. Box 9004, Abha 61413, \\ Kingdom of Saudi Arabia \\ ${ }^{2}$ Chemistry and Nuclear Physics Institute, Atomic Energy Commission, P.O. Box 3001, Khartoum \\ 11111, Sudan \\ ${ }^{3}$ Department of Chemistry, College of Science, Princess Nourah Bint Abdulrahman University, \\ Riyadh, Saudi Arabia \\ ${ }^{4}$ Higher Institute of Biotechnology of Sfax (ISBS), Sfax University, P.O. Box 263, Sfax 3000, Tunisia \\ *E-mail: tahooon_87@yahoo.com
}

doi: $10.20964 / 2020.04 .13$

Received: 15 November 2019 / Accepted: 23 December 2019 / Published: 10 March 2020

Ascorbic acid (AA) is one of the most important biomolecules that play an important role in the synthesis of collagen, norepinephrine and neuronal hormones in addition to its role in folic acid tyrosine and tryptophan metabolisms. Also, vitamin $\mathrm{C}$ participates in many biochemical processes; it functions as a cofactor for several enzymes, enhances the intestinal iron absorption and is involved in carnitine biosynthesis and cellular metabolism. Various analytical methods with high sensitivity and selectivity have been developed for ascorbic acid quantitative detection. Recently, a highly sensitive, effective and rapid ascorbic acid detection was achieved using nanomaterials-based sensors. Herein, we discussed the latest published articles for the ascorbic acid sensors based on nanomaterials and their fabrication.

Keywords: Ascorbic acid; Electrochemical sensors; Nanomaterials

\section{FULL TEXT}

(C) 2020 The Authors. Published by ESG (www.electrochemsci.org). This article is an open access article distributed under the terms and conditions of the Creative Commons Attribution license (http://creativecommons.org/licenses/by/4.0/). 